Thiago Henrique Ament

\title{
RECURSO DE REVISTA REPETITIVO: \\ ENTRE OS PRECEDENTES DA COMMON LAW \\ E O JULGAMENTO POR CAUSA PILOTO
}

Dissertação apresentada à Banca Examinadora do Programa de Pós-Graduação em Direito, da Faculdade de Direito da Universidade de São Paulo, como exigência parcial para obtenção do título de Mestre em Direito, na área de concentração Direito do Trabalho e da Seguridade Social, sob a orientação do Professor Dr. Estêvão Mallet.

Universidade de São Paulo

Faculdade de Direito da USP

São Paulo-SP

2017 
Catalogação da Publicação

Serviço de Biblioteca e Documentação

Faculdade de Direito da Universidade de São Paulo

Ament, Thiago Henrique

Recurso de revista repetitivo: entre os precedentes da common law e o julgamento por causa piloto / Thiago Henrique Ament; orientador Estêvão Mallet -- São Paulo, 2017.

192

Dissertação (Mestrado - Programa de Pós-Graduação em Direito do Trabalho e Seguridade Social) - Faculdade de Direito, Universidade de São Paulo, 2017.

1. I. Mallet, Estêvão, orient. II. Título. 
Nome: AMENT, Thiago Henrique

Título: Recurso de revista repetitivo: entre os precedentes da common law e o julgamento por causa piloto

Dissertação apresentada à Banca Examinadora do Programa de Pós-Graduação em Direito, da Faculdade de Direito da Universidade de São Paulo, como exigência parcial para obtenção do título de Mestre em Direito, na área de concentração Direito do Trabalho e da Seguridade Social, sob a orientação do Professor Dr. Estêvão Mallet.

Aprovado em:

Banca Examinadora

Prof. Dr. Instituição:

Julgamento: Assinatura:

Prof. Dr. Instituição:

Julgamento: Assinatura:

Prof. Dr. Instituição:

Julgamento: Assinatura: 


\section{RESUMO}

AMENT, T. H. Recurso de revista repetitivo: entre os precedentes da common law e o julgamento por causa piloto. 186 p. Dissertação de Mestrado - Faculdade de direito, Universidade de São Paulo, São Paulo-SP, 2017.

A Lei n. ${ }^{\circ}$ 13.015/14 confere grande importância às decisões judiciais do TST, principalmente quando proferidas em julgamentos por amostragem, de recursos de revista repetitivos, tendência que também é observada no novo Código de Processo Civil (Lei n. ${ }^{\circ}$ 13.105/15). A técnica de formação de precedentes brasileiros vinculada ao julgamento de casos repetitivos coloca em questão a real finalidade do legislador com a reforma processual: garantir a unidade do direito, sua estabilidade e coerência ou possibilitar uma maior vazão processual, com julgamentos numericamente mais eficientes. Estamos falando de precedentes ou de uma técnica para julgamento de litígios de massa, por meio de causa piloto, como o procedimento modelo alemão e as ordens de litígio em grupo inglesas? A análise do regramento do novo instituto processual trabalhista é realizada a partir de considerações sobre a natureza jurídica, interpretação e aplicação dos precedentes judiciais na origem da common law, procurando-se demonstrar que a decisão com base em precedente não pode ser realizada de forma mecânica e automática. Examinam-se, também, os conceitos de ratio decidendi e obter dicta, bem como a técnica do distinguishing que é essencial para que um sistema de precedentes seja capaz de realizar ao mesmo tempo o princípio da isonomia e o direito ao reconhecimento de diferenças.

Palavras Chaves: Recurso de revista repetitivo. Precedentes. Ações teste. 


\begin{abstract}
AMENT, T. H. Recurso de revista repetitivo: entre os precedentes da common law e o julgamento por causa piloto. 186 p. Dissertação de Mestrado - Faculdade de direito, Universidade de São Paulo, São Paulo-SP, 2017.

Law No. 13.015/14 assigns great importance to the judicial decisions of TST, especially when judgments by sampling, of repetitive judicial appeal resources, a trend that is also observed in the new Code of Civil Procedure (Law no. 13.105/15). The technique of forming Brazilian precedents linked to the judgment of repetitive cases calls into question the real purpose of the legislator with the procedural reform: to guarantee the unity of the law, its stability and coherence or to allow a greater process flow, with numerically more efficient judgments. Are we talking about precedents or a technique for judgment of mass litigation, by means of test actions, such as the German model procedure and the English group litigation orders? The analysis of the new labor process institute is based on considerations of the legal nature, interpretation and application of the judicial precedents of common law, with the aim of demonstrating that the decision based on precedent can not be performed mechanically and automatic. It also examines the concepts of ratio decidendi and obter dicta, as well as the technique of distinguishing which is essential for a system of precedent to be able to achieve at the same time the principle of isonomy and the right to recognize differences.
\end{abstract}

Key words: Repetitive judicial appeal resources. Precedent. Test actions. 


\section{LISTA DE ABREVIATURAS}

Art.

Artigo

$\mathrm{CF}$

Constituição Federal

CLT

Consolidação das Leis do Trabalho

$\mathrm{CNJ}$

Conselho Nacional de Justiça

CPC

Código de Processo Civil

CPR's

Civil procedure rules

EC

Emenda Constitucional

GLO

Group Litigation Order

IRDR

Incidente de resolução de demandas repetitivas

$\mathrm{KapMuG}$

Capital Markets Model Case Act

Min.

Ministro

RE

Recurso extraordinário

Rel.

Relator

REsp

Recurso especial

RISTF

Regimento Interno do Supremo Tribunal Federal

STF

Supremo Tribunal Federal

STJ

Superior Tribunal de Justiça

SV

Súmula Vinculante

TST

Tribunal Superior do Trabalho

USP

Universidade de São Paulo 
SUMÁRIO

INTRODUÇÃO

1. FAMÍlIAS JURÍdICAS. APROXIMAÇÃO CRÍTICA E OS NOVOS CONTORNOS DA FUNÇÃO JURISDICIONAL. TENDÊNCIA MUNDIAL E NO DIREITO BRASILEIRO

1.1 As grandes famílias jurídicas: civil law e common law .... 15

1.2. O positivismo e a jurisdição no Estado Liberal 18

1.3 Iniciada a transição: o retorno do fato (dos costumes) e dos valores para o mundo do Direito 22

1.4 Tendência mundial de superação das distinções entre civil law e common law: transformação da função jurisdicional na passagem do Estado Liberal para o Estado Constitucional 25

1.5 Tendência no Brasil de valorização do direito jurisprudencial: antecedentes históricos. 31

1.6 A reforma trabalhista da Lei n. ${ }^{\circ} 13.467 / 17$ e o retorno da figura do juiz boca da lei 34

2. PRECEDENTE JUDICIAL 39

2.1. Conceito e elementos do precedente judicial 40

2.1.1 Natureza jurídica do precedente judicial 43

2.1.2 Obter dictum (ou dicta) 44

2.1.3 A identificação da ratio decidendi 45

2.1.4 Classificação dos precedentes segundo o grau de vinculação 49

2.2 Técnicas de utilização dos precedentes: confronto e distinção 51

2.2.1 Distinguishing 51 
2.2.2 Distinguishing no TST 59

2.3 Técnicas de superação do precedente: overruling (total) e overriding (parcial) ......... 64

2.3.1 Overruling difuso e overruling concentrado 67

2.3.2 Fundamentação do overruling 68

2.3.3 Signaling e antecipatory overruling 69

2.3.4 A eficácia temporal da revogação do precedente 69

2.3.4.1 Modulação dos efeitos da decisão revisora e o julgamento alerta 70

2.3.5 O problema da aplicação retroativa das súmulas 75

2.3.6 Observações conclusivas do capítulo: precedente, jurisprudência e súmula 77

\section{LITIGIOSIDADE DE MASSA E O JULGAMENTO POR CAUSA PILOTO}

3.1 Contextualização: o problema das demandas repetitivas e o processo civil clássico .. 82 3.1.1 Insuficiência do regramento atual brasileiro das ações coletivas para a solução de litígios de massa 83

3.2. Novas técnicas de decisões padronizadas: julgamento por amostragem no direito brasileiro e estrangeiro 87

3.2.1 Recurso extraordinário, especial e de revista repetitivos 88

3.2.2 Procedimento-modelo alemão (Musterverfahren) 89

3.2.3 Ordens de litígio em grupo (GLO): o julgamento por causa piloto na Inglaterra .... 94 3.2.4 Incidente de resolução de demandas repetitivas no CPC de 2015 e sua aplicação no processo do trabalho 98

4. RECURSO DE REVISTA REPETITIVO: NATUREZA JURÍDICA E

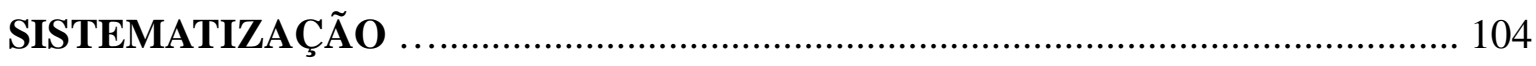

4.1 Recurso de revista no processo do trabalho e a crise de identidade do TST . 104 
4.1.1 Evolução dos precedentes no processo do trabalho: prejulgado trabalhista, súmulas, orientação jurisprudencial, precedente normativo ......................................................... 107

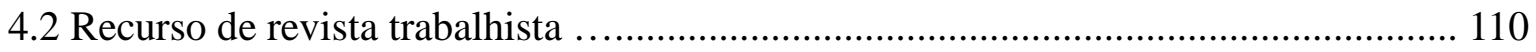

4.2.1 Recurso de revista repetitivo: aspectos históricos e objetivos .............................. 111

4.2.2 Natureza jurídica do recurso de revista repetitivo, cabimento e objeto: apenas

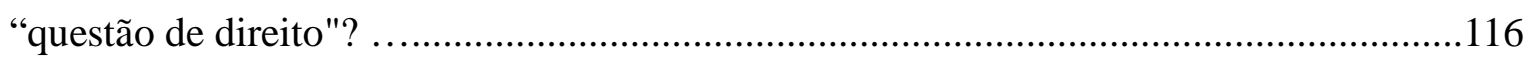

\section{PROCEDIMENTO DO INCIDENTE DE RECURSO DE REVISTA REPETITIVO}

5.1. Fase inicial: legitimidade e análise do requerimento de afetação da questão jurídica 124

5.1.1 Formação do procedimento modelo: a importância da escolha 127

5.1.2 Os efeitos da admissibilidade: publicidade e divulgação da instauração do incidente 129

5.1.2.1 Sobrestamento dos recursos repetitivos 131

5.1.2.2 Distinção do caso e prosseguimento do processo 135

5.2 Fase de instrução: participação democrática na formação da decisão padrão 137

5.2.1 Escolha dos líderes 137

5.2.2 Amicus curiae 138

5.2.3 Audiências públicas 143

5.3 Fase de julgamento do incidente de recurso de revista repetitivo 144

5.3.1 Fundamentos da decisão padrão 148

5.4 Fase recursal: cabimento e legitimidade para interposição de recurso contra a decisão do incidente 149

6. EFEITOS DA DECISÃO E SUA REVISÃO 154

6.1 Processos sobrestados e futuros 154 


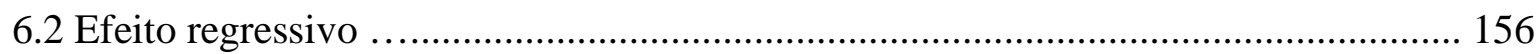

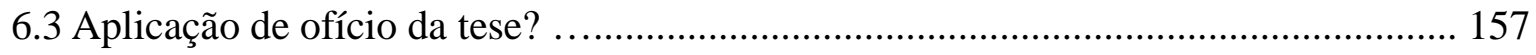

6.4 Aplicação da tese jurídica e distinção: um grande desafio ....................................... 159

6.5 Superação do entendimento: procedimento e ônus argumentativo ............................ 164

7. TESTE FINAL: O INCIDENTE DE RESOLUÇÃO DE RECURSOS DE REVISTA REPETITIVOS É COMPATÍVEL COM O DIREITO CONSTITUCIONAL

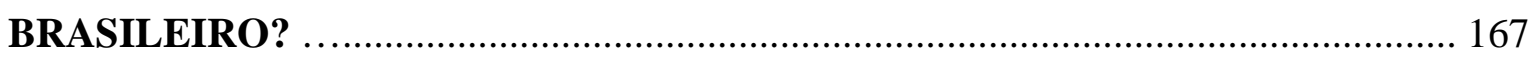

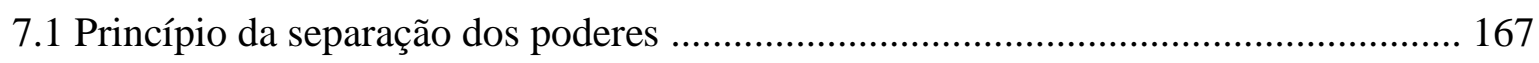

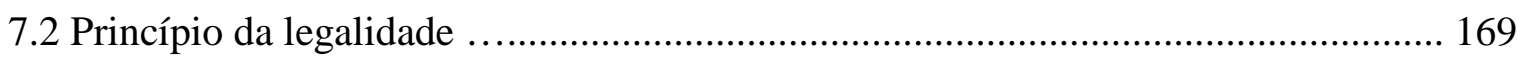

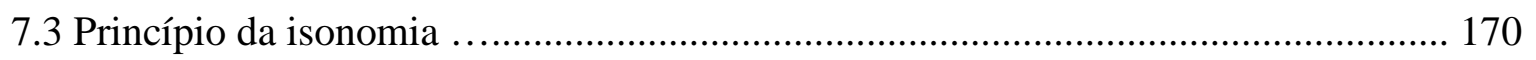

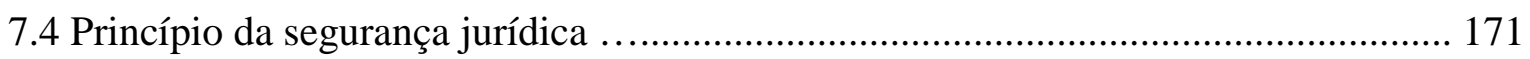

7.5 Princípio da motivação das decisões judiciais ...................................................... 171

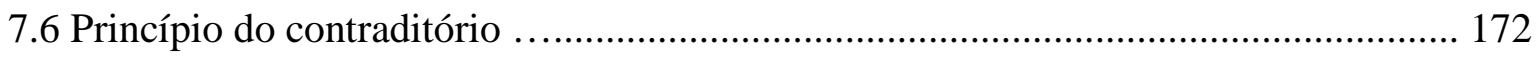

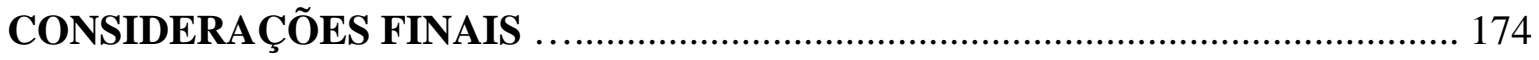

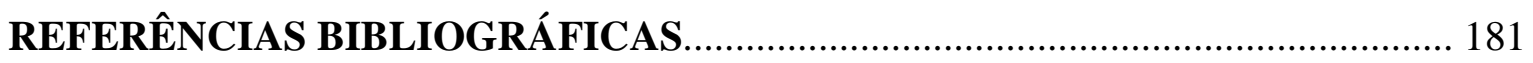




\section{INTRODUÇÃO}

A Lei n. ${ }^{\circ}$ 13.015/14 confere grande importância às decisões judiciais do TST, principalmente quando proferidas em julgamentos por amostragem, de recursos de revista repetitivos, tendência que também é observada no novo Código de Processo Civil (Lei n. ${ }^{\circ}$ 13.105/15).

Trata-se de uma das maiores reformas processuais na sistemática recursal da $\mathrm{CLT}^{1}$ e que importará uma nova realidade, na medida em que altera paradigmas no direito brasileiro tradicionalmente desenvolvido sobre base muito distinta, a partir de inspiração no sistema da civil law.

De fato, a rígida distinção histórica entre os sistemas da common law e da civil law, por meio da afirmação de que os primeiros seriam fundamentados nos precedentes e o segundo sobre a lei escrita, perdeu muito de seu significado nos dias atuais. ${ }^{2}$ Em todo o mundo, cada vez mais os sistemas da common law fazem uso da lei escrita e os sistemas da civil law conferem mais importância à jurisprudência, verificando-se uma aproximação entre as duas principais famílias do direito. No ordenamento jurídico brasileiro, não é diferente.

O problema é que os juristas nacionais, juízes, promotores, defensores e advogados, não estão acostumados a decidir e argumentar diante de normas abertas e

${ }^{1}$ Conforme MALLET, "Embora a Lei n. 13.015 tenha alterado apenas quatro artigos da CLT (894, 896, 897A e 899), e introduzindo dois novos (896-B e 896-C), nela provavelmente se contém a mais ampla modificação do sistema recursal trabalhista já realizada..." (MALLET, Estêvão. Reflexões sobre a Lei $n$. 13.015/2014. Revista do Tribunal Superior do Trabalho, v. 80, p. 74-111, 2014)

2 A título de exemplo, confiram-se diversos estudos sobre essa aproximação de sistemas jurídicos: TARUFFO, Michele. Observações sobre os modelos processuais de civil law e de common law. Revista de Processo: RePro, São Paulo, n. 110, v. 28, abr/jun 2003, p. 141-158; MARINONI, Luiz Guilherme. Aproximação crítica entre as jurisdições de civil law e de common law e a necessidade de respeito aos precedentes no Brasil. Capítulo XXVI. DIDIER JR. Fredie (coord.). Teoria do Processo - Panorama Doutrinário Mundial Vol. 2. Salvador: Ed. JusPodivm, p. 533-588; BARROSO, Luis Roberto. Neoconstitucionalismo e constitucionalização do Direito. O triunfo tardio do Direito Constitucional no Brasil. Disponível em: <http://jus.com.br/imprimir/7547/neoconstitucionalismo-e-constitucionalizacao-dodireito>. Acesso em: 23/09/2015; BARROSO, Luiz Roberto; MELLO, Patrícia Perrone Campos. Trabalhando com uma nova lógica: a ascensão dos precedentes no direito brasileiro. Disponível em: http://s.conjur.com.br/dl/artigo-trabalhando-logica-ascensao.pdf. Acesso em: 03/11/16. 
incompletas, tendo em vista a tradição da lei escrita, possuindo pouca familiaridade com o sistema de precedentes judiciais. ${ }^{3}$ A partir de agora, conceitos típicos dos sistemas judiciais de precedentes e pouco conhecidos do processo do trabalho brasileiro, tais como: ratio decidendi e obiter dictum, bem como sobre as técnicas de aplicação e superação dos precedentes, tais como distinghisinhg, overruling, express e impleid overruling, overruling prospectivo, retrospective e antecipatory, overriding, definitivamente, passarão a integrar o corpo da argumentação decisória e postulatória trabalhista.

O desafio do momento é grande porque o que se pretende construir é um sistema que seja capaz de absorver as tendências de universalização do direito e concretização do princípio da isonomia sem, contudo, descurar-se das particularidades do caso concreto, por meio da fixação de uma justa norma jurídica individual.

Releve-se que os precedentes nos países da tradição da common law são entendidos como um instituto altamente complexo e jamais possuíram a pretensão de trazer uma solução pronta e acabada, de antemão, para todos os casos futuros. Ao contrário, os precedentes funcionam como um ponto de partida, devem ser sempre interpretados e terem justificada de forma adequada a sua aplicação ou não diante do caso concreto em julgamento. $^{4}$

Diante do não estabelecimento de plano do que é o precedente pelo órgão julgador na matriz da common law, diversas técnicas foram desenvolvidas para sua interpretação e principalmente a definição do seu aspecto vinculante, destacando-se o teste de Wambaugh e o método desenvolvido por Arthur Goodhart.

\footnotetext{
${ }^{3}$ Neste sentido, destacam NUNES, Dierle; Rafaela Lacerda; Newton Rodrigues Miranda: "Tanto na doutrina, quanto na prática jurídica, percebe-se uma enorme confusão conceitual no processo argumentativo ao se defender a aplicação de "súmulas", "súmulas vinculantes", "jurisprudência", "julgados" e "precedentes". Nesse processo não é raro que os operadores jurídicos defendam como "vinculante" jurisprudência preventiva, de modo que o precedente é criado e aplicado ao mesmo tempo. E não apenas as partes sofrem dessa confusão, mas os próprios juízes que aplicam precedentes em suas decisões: falta a habilidade de manejo do distinguishing e do overruling e no respeito e continuidade às decisões proferidas pelas Cortes." (O uso do precedente judicial na prática judiciária brasileira: uma perspectiva crítica. Rev. Fac. Direito UFMG, Belo Horizonte, n. 62, jan./jun. 2013, p. 179).

${ }^{4}$ Com efeito, estabelece o art. $489, \S 1^{\circ}$ do $\mathrm{CPC}$, inciso $\mathrm{V}$, que não se considera fundamentada qualquer decisão que: "se limitar a invocar precedente ou enunciado de súmula, sem identificar seus fundamentos determinantes nem demonstrar que o caso sob julgamento se ajusta àqueles fundamentos".
} 
Com efeito, um apego desmensurado a decisões anteriores, aplicadas de forma mecânica e sem um indispensável juízo de ponderação, poderia levar a um engessamento do direito ou mesmo a uma negação de acesso à justiça, frustrando o direito constitucional das partes quanto à apreciação de particularidades relevantes dos novos casos. De alguma forma, pode-se dizer que até hoje sobrevivemos sem uma adequada teoria de precedentes pois as decisões de nossos Tribunais sempre foram consideradas meramente persuasivas, tendo em vista nossa tradição do civil law. Todavia, quanto maior a atribuição de poder vinculante à razão de decidir do julgamento pretérito, maior será a necessidade de desenvolvimento de técnicas de confronto que permitam o exame de adequação ou a não da utilização da mesma razão de decidir para o novo caso. Trata-se da técnica da distinção que é indispensável num sistema de precedentes e conhecida nos países da common law como distiguishing.

Assim, revela-se imperioso o estudo sobre a teoria dos precedentes e seus institutos para sua correta adaptação ao processo do trabalho brasileiro, inclusive como forma de se evitar o engessamento da jurisprudência, considerada a missão do Direito do Trabalho de promover a justiça, orientar condutas e promover a igualdade, garantindo a segurança jurídica e a coerência do sistema.

O presente trabalho será dividido em seis partes. No primeiro capítulo, serão analisados os fundamentos que determinam o movimento mundial de aproximação entre as famílias jurídicas do civil law e da common law, com suas repercussões no ordenamento jurídico brasileiro. No segundo capítulo, serão revisitados os principais conceitos da teoria dos precedentes e que orientam o seu funcionamento nos países da common law, fazendose uma crítica sobre como os tribunais trabalhistas têm ou não levado em consideração a sua própria jurisprudência. No terceiro capítulo, o estudo voltará atenção para o problema dos litígios de massa e sobre como a técnica do julgamento por amostragem ${ }^{5}$ tem sido utilizada para seu enfrentamento no direito comparado e brasileiro, com destaque para o

\footnotetext{
${ }^{5} \mathrm{O}$ julgamento por amostragem de casos repetitivos é uma técnica processual adotada em diversos países e que permite a seleção de um ou mais casos para a resolução da questão comum. Posteriormente, esta decisão é aplicada aos demais processos que ficaram sobrestados aguardando a decisão da questão comum. Trata-se de técnica que possui muito mais afinidade com o procedimento modelo alemão (Musterverfahren) e as ordens de litígio em grupo inglesas (GLO), do que em relação ao sistema de precedentes anglo-saxão.
} 
procedimento-modelo alemão e as ordens de litígio em grupo inglesas. No capítulo quarto, serão analisadas as origens históricas e a natureza jurídica do recurso de revista repetitivo a partir da análise sobre o papel a ser realizado pelo TST na posição de Corte de vértice da Justiça do Trabalho. O capítulo quinto empreenderá uma análise crítica sobre o procedimento do recurso de revista repetitivo tendo em vista outros regramentos de ações teste já existentes como o musterverfahren alemão e o julgamento por causa piloto da Inglaterra. O sexto capítulo cuidará do exame dos efeitos da decisão sobre os processos não afetados e dos mecanismos para a revisão da tese jurídica firmada no julgamento por causa piloto. Finalmente, o regramento do novo instituto será testado à luz de diversos princípios constitucionais, com abordagem das vantagens e desvantagens que o novo incidente poderá ou não trazer à efetividade das normas trabalhistas. 


\section{CONSIDERAÇÕES FINAIS}

O reconhecimento da força normativa dos princípios constitucionais e a utilização pelo legislador infraconstitucional de cláusulas gerais e conceitos legais indeterminados, promoveram uma profunda alteração na teoria da norma jurídica e do ordenamento jurídico, conferindo ao julgador grande poder para a realização de justiça conforme as circunstâncias do caso concreto.

A moderna hermenêutica reconhece uma clara diferenciação entre texto e norma, sendo esta o resultado da interpretação daquele. Por sua vez, a interpretação somente pode ser realizada a partir da análise dos fatos do caso concreto à luz do direito objetivo. A interpretação não pode ser compreendida fora da aplicação da norma.

Vive-se uma tendência mundial de superação das distinções entre a civil law e a common law, de modo que não é mais possível negar a importância das decisões anteriores sobre casos semelhantes na orientação de condutas de trabalhadores e empregadores, principalmente quanto oriundas de cortes de vértice.

Por outro lado, a consequência natural de uma sociedade de massas é a existência de demandas similares e que se encontram recebendo respostas totalmente diferentes, trazendo indícios de injustiça. ${ }^{287}$ Ainda que o estabelecimento de um conceito de justiça seja uma das tarefas mais difíceis da filosofia do Direito, o certo é que a isonomia no tratamento de casos similares é um dos seus critérios mais importantes e presentes em qualquer definição que se pretenda estabelecer.

Além da violação reiterada do princípio da isonomia, existe o problema do congestionamento do Poder Judiciário com demandas que trazem as mesmas questões jurídicas, circunstância que praticamente inviabiliza a atuação do TST como uma verdadeira corte de precedentes.

${ }^{287}$ Neste quadro, conforme já assinalava MESQUITA: “a uniformização da jurisprudência, considerada por muitos um mal, porque conduziria à estagnação do direito, visa na realidade a impedir que o comando contido na lei se multiplique indiscriminadamente ao sabor das interpretações que se possam extrair do texto legal, que, na sua variedade podem chega ao ponto de se tornarem contraditórias, em prejuízo da própria imperatividade da lei. E, neste sentido, os instrumentos processuais destinados à uniformização da jurisprudência constituem, sem dúvida, antes um bem que um mal." (MESQUITA, José Ignácio Botelho de. A súmula da jurisprudência dominante no Supremo Tribunal Federal, in Teses, Estudos e Pareceres de Processo Civil, vol. 2, São Paulo: RT, 2005, p. 217). 
Ressalte-se que o direito do trabalho não é um direito meramente individual, configurando um conjunto de normas destinadas à regulação jurídica do modo de produção capitalista e à garantia de um patamar civilizatório mínimo aos trabalhadores. ${ }^{288}$ A falta de isonomia no tratamento de idênticas questões jurídicas definidoras dos direitos trabalhistas daqueles que ombreiam é algo muito caro ao Direito do Trabalho.

A insuficiência das ações coletivas para diminuição do número de ações de massa, levou diversos ordenamentos jurídicos a desenvolverem técnicas para o tratamento coletivo de questões comuns em demandas individuais, tais como o procedimento-modelo alemão (Musterverfahren) e as ordens de litígio em grupo inglesas (GLO). ${ }^{289} \mathrm{O}$ ponto de semelhança destes procedimentos é uma cisão cognitiva e decisória, realizada a partir da escolha de um modelo, no qual serão apreciadas as questões comuns aos casos similares, ficando a decisão do caso concreto para o juízo do processo originário. Nestas técnicas de julgamento por amostragem do direito comparado, a decisão alcança também questões de fato, mesmo porque é muito difícil o estabelecimento de uma clara diferença entre o que seja matéria de fato e matéria de direito.

A Lei n. ${ }^{\circ}$ 13.015/14 introduz o incidente de recurso de revista repetitivo no processo do trabalho, cujo objeto é exclusivamente matéria de direito. Todavia, é bastante difícil sustentar que o novel procedimento trabalhista de julgamento por amostragem o TST estaria limitado a decidir questões de direito. Confira-se, a título de exemplo, o Tema 7 da Tabela de recursos recurso de revista repetitivos que discute sobre a existência ou não de fraude na alienação de ativos 40 dias antes de aprovação do plano de recuperação judicial, trazendo decisão sobre um fato concreto e objeto de alegação em inúmeros

288 Muito embora combativo em relação a ideia do precedente na Justiça do Trabalho, Souto Maior reconhece que: "Nesse contexto, o processo do trabalho não se volta apenas à solução do conflito no caso concreto, aplicando a norma ao fato. Impingi-lhe a obrigação de implementar uma política judiciária destinada à correção da realidade, de modo a impedir que novas agressões jurídicas, com mesmo potencial ofensivo, se realizem, valendo lembrar que o Direito do Trabalho não é um direito individual (ainda que a doutrina, de forma inadvertida lhe tenha cunhado esse título), constituindo, isto sim, um arcabouço de regulação do modo de produção capitalista. O descumprimento reiterado dos direitos trabalhistas desestabiliza toda a sociedade em detrimento da própria economia." (MAIOR, Jorge Luiz Souto. O conflito entre $o$ novo $\quad$ CPC $e$ o processo do trabalho. Disponível em:http://www.migalhas.com.br/arquivos/2015/7/art20150708-06.pdf. Acesso em: 31/01/17).

289 Não se desconhece o relevante papel desempenhado pelas ações coletivas no processo do trabalho, todavia, defende-se neste trabalho a possibilidade de sua convivência com a técnica do julgamento por recurso piloto, como forma de garantir efetividade e isonomia ao direito do trabalho. 
processos. Tal circunstância aproxima bastante o julgamento deste incidente de recurso de revista repetitivo do procedimento modelo alemão, cuja origem foi a recorrente alegação de fraude na divulgação de informações falsas pela empresa Telekom, com prejuízos causados a inúmeros investidores do mercado financeiro.

Por outro lado, ainda que objetivando firmar a orientação predominante do Tribunal, é imperioso destacar que o sistema de formação de precedentes por meio do julgamento de recursos de revista repetitivos é bastante diferente dos precedentes da common law, pelo menos em quatro aspectos relevantes: a) nos países da common law os precedentes são formados de modo difuso e não de modo concentrado como nas hipóteses dos arts. 896-C da CLT e art. 927 do CPC; b) no direito anglo-americano os precedentes são reconhecidos pelo juiz do caso sucessivo e não estabelecidos de plano pelo julgador do processo originário, como no caso dos recursos de revista repetitivos que buscam fixar uma tese jurídica; c) na common law o precedente não é declarado como uma fórmula pronta e acabada com a pretensão de solução de todos os casos; ao contrário, os seus limites e âmbito de aplicação são delineados aos poucos, conforme reconhecidos pelos julgamentos posteriores e estabelecimento de distinções (distinguishing); d) na tradição da common law o respeito aos precedentes é aceito como uma questão cultural, não existindo a necessidade de uma norma legal estabelecendo tal obrigatoriedade. ${ }^{290}$

Todavia, estas substanciais diferenças não são suficientes para afastar a necessidade de uma teoria sobre a ratio decidendi e o aprimoramento das técnicas de distinção, porquanto o direito é um fenômeno complexo e indissociável dos fatos e valores da vida, de modo que a interpretação será sempre necessária. Caso contrário, correr-se-iam dois grandes riscos, ${ }^{291}$ igualmente prejudiciais a ideia de justiça:

a) diante da pressão de números e sob a justificativa de realização do princípio da razoável duração do processo, da adoção de um sistema de precedentes tão rígido que

\footnotetext{
${ }^{290}$ A vinculação de determinados países da civil law à lei escrita é tal monta que torna necessária a existência de uma lei fixando a necessidade de respeito aos precedentes, como no caso do Brasil.

291 Conforme adverte MESQUITA, o grande risco da uniformização de jurisprudência e do sistema de precedentes é o afastamento das circunstâncias do caso concreto. (MESQUITA, José Ignacio Botelho de. A súmula da jurisprudência dominante no Supremo Tribunal Federal, in Teses, Estudos e Pareceres de Processo Civil, vol. 2, São Paulo: RT, 2005, p. 220)
} 
acabe afastando-se das circunstâncias do caso concreto, conferindo tratamento igual a casos substancialmente diferentes, mediante a citação de precedentes de forma totalmente descontextualizada;

b) o estabelecimento de distinções inconsistentes com a frustração do objetivo do legislador de conferir o mesmo tratamento a demandas similares, mantendo-se o estado atual de julgamento pelo magistrado de acordo com a sua livre consciência e sem qualquer compromisso com as decisões anteriores.

No século do iluminismo, apostou-se na completude da lei e onipotência do legislador. Tempos depois, verificou-se que o direito é um fenômeno complexo e indissociável dos fatos e valores da vida, de modo que a interpretação será sempre necessária. A lei é obrigatória e fundamenta decisões completamente diferentes. O próprio Hanz Kelsen, considerado legalista de estirpe, define a lei com uma moldura, não possuindo significado unívoco, até mesmo pela utilização da linguagem.

Ainda que a Lei n. ${ }^{\circ}$ 13.015/14, o Ato 491 da Presidência do Tribunal Superior do Trabalho e o CPC de 2015 estabeleçam que a tese oriunda de julgamento de recurso repetitivo é formalmente vinculante, da mesma forma o direito jurisprudencial deverá ser interpretado. Não é possível apostar todas as fichas que uma disciplina legal sobre precedentes e julgamento de demandas repetitivas será a solução para a enxurrada de processos que assolam os tribunais do país. ${ }^{292}$

\footnotetext{
292 Conforme já advertiu TARUFFO: "Naturalmente ciò solleva un rilevante problema ulteriore: poiché le circostanze che costituiscono i fatti dei caso sono infinite, e sono anche infinite le loro possibili descrizioni, si tratta di determinare quali sono i particulars che si ritengono significativi e rilevanti per l'Interpretazione e applicazione della norma alia quate si fa riferimento. Al riguardo non esistono soluzioni semplici che possano valere automaticamente per qualunque decisione. Anche il riferimento alia fattispecie definita in termini generali dalla norma serve solo -per cosí dire- a dare il via all'analisi dei fatti, fornendo un paradigma iniziale, che in reaità non è piü che unipotesi provvisoria, di rilevanza giuridica. E' però muovendo da questa ipotesi, ed eventualmente formulandone altre chesiano progressivameníe più adeguate alie drcostanze dei caso concreto che il giudice, attraverso la c.d. splrale ermeneutica, giunge a stabiüre qualí sono le drcostanze rilevanti dei caso. Poiché peraltro in questo procedimento di trial and error o -se si preferisce- di abduzione interpretativa, non vi è nulla di meccanico o predeterminato, è un'attlvità eminentemente creativa quella che porta ti giudice ad attribuire rilevanza a determinati partículars dei caso, e a modellare su di essi l'interpretazione della norma che intende applicare." (TARUFFO, Michele. Le funzioni delle Corti Supreme tra uniformità e giustizia, in DIDIER JR., Fredie et alli (coords.), Precedentes. Salvador: JusPodivm, 2015, p. 251/262).
} 
A atividade interpretativa é intrínseca ao ato de julgar. ${ }^{293}$ A própria origem da palavra "sentença" remonta a ideia de "sentimento" do juiz em relação à justiça do caso. Em pleno século XXI, não é possível pretender o resgate da figura do "juiz boca de lei" com uma nova roupagem de "juiz boca precedente". 294

A grande virada hermenêutica da Lei n. ${ }^{\circ}$ 13.015/14 e do novo CPC não está exatamente no sistema formal de precedentes de questionável constitucionalidade, ${ }^{295}$ mas em buscar garantir uma evolução ordenada do direito, impondo um maior ônus argumentativo ao julgador quanto às interpretações jurisprudenciais existentes sobre o sentido das normas jurídicas que irá aplicar.

Destacando a importância da evolução ordenada do Direito, MESQUITA296 assinala que deve ser

(...) encontrada no ponto em que a irreprimível vocação evolutiva do direito se realize de modo disciplinado, sem sacrifício da indispensável segurança jurídica, mas sem sacrificar também a necessidade da permanente adequação do direito à constante dos fatos sociais.

293 O grande perigo do incidente de recurso de revista repetitivo é de retorno ao formalismo interpretativo, do positivismo clássico.

294 Nesse sentido, também: STRECK, Lenio; ABBOUD, Georges. O NCPC e os precedentes - afinal do que estamos falando?, in DIDIER JR., Fredie et alli (coords.), Precedentes - Coleção Grandes Temas do Novo CPC, vol. 3, p. 175/182.

295 Em comentário ao art. 927 do CPC, NERY JR e NERY, sustentam que: “Juízes e tribunais observarão. O texto normativo impõe, imperativamente, aos juízes e tribunais que cumpram e apliquem os preceitos nele arrolados. Trata-se de comando que considera esses preceitos como abstratos e de caráter geral, vale dizer, com as mesmas características da lei. Resta analisar se o Poder Judiciário tem autorização constitucional para legislar, fora do caso da Súmula Vinculante do STF, para o qual a autorização está presente na CF 103-A. Somente no caso da súmula vinculante, o STF tem competência constitucional para estabelecer preceitos de caráter geral. Como se trata de situação excepcional - Poder Judiciário a exercer a função típica do Poder Legislativo - a autorização deve estar expressa no texto constitucional e, ademais, se interpreta restritivamente, como todo preceito de exceção. Observar decisão: a) em RE e REsp repetitivos, b) em incidente de assunção de competência, c) em incidente de resolução de demandas repetitivas (IRDR), d) entendimento constante da súmula simples do STF em matéria constitucional, e) entendimento constante da súmula simples do STJ em matéria infraconstitucional (rectius: federal) e f) do órgão especial ou do plenário do tribunal a que estejam vinculados os juízes significa que esses preceitos vinculam juízes e tribunais, vinculação essa de inconstitucionalidade flagrante. O objetivo almejado pelo CPC 927 necessita ser autorizado pela CF. Como não houve modificação na CF para propiciar ao Judiciário legislar, como não se obedeceu o devido processo, não se pode afirmar a legitimidade desse instituto previsto no texto comentado (...)." (NERY JR., Nelson; ANDRADE NERY, Rosa Maria de. Comentários ao Código de Processo Civil. São Paulo: RT, 2015).

296 MESQUITA, José Ignacio Botelho de. A súmula da jurisprudência dominante no Supremo Tribunal Federal, in Teses, Estudos e Pareceres de Processo Civil, vol. 2, São Paulo: RT, 2005, p. 217. 
Isto não significa que o juiz seja um escravo do precedente, abdicando-se de sua capacidade de convencimento racional. O precedente é o ponto de partida, não necessariamente o fim da atividade interpretativa.

Os valores da justiça, isonomia e segurança jurídica traduzem a exigência de um maior ônus argumentativo ao desprezar as decisões anteriores em casos semelhantes, até mesmo como forma de garantia da coerência de um ordenamento jurídico que possua pretensão de racionalidade. Afinal, o que realmente vincula num sistema de direito positivado é a Constituição e as leis.

O incidente de resolução de recurso de revista repetitivos possui natureza jurídica de procedimento autônomo e caráter híbrido, assimilando institutos dos precedentes da common law e dos julgamentos por procedimento-modelo. ${ }^{297}$ Conforme a natureza preponderante dos temas escolhidos para julgamento por meio do incidente, o novo instituto pode ser utilizado para: (a) a resolução de demandas repetitivas de litigantes habituais, (b) a definição de sentido e alcance da legislação de proteção ao trabalho, bem como (c) a resolução de questões jurídicas processuais repetidas em inúmeras reclamações trabalhistas.

O manejo dessa ferramenta poderá trazer grandes benefícios à efetividade do Direito do Trabalho, evitando-se a dispersão jurisprudencial que enfraque as decisões da Justiça do Trabalho, principalmente em tempos de ataques constantes sofridos em momentos de crise econômica como vivenciados atualmente. Discordamos da opinião daqueles que defendem que as reformas do processo comum e da CLT para o reconhecimento do direito jurisprudencial somente atendam aos interesses do capitalismo,

\footnotetext{
${ }^{297} \mathrm{Na}$ realidade, a depender do tipo e amplitude da questão jurídica selecionada, o procedimento trabalhista estará mais próximo dos precedentes da common law ou do julgamento por causa piloto. Por exemplo, no caso do Tema 1 da Tabela de recursos de revista repetitivos do TST ("A exigência de apresentação de certidão de antecedentes criminais pelos candidatos ao emprego gera dano moral?), verifica-se uma maior aproximação com os precedentes da common law encontrados a partir da universalização da razão de decidir para casos semelhantes. Por outro lado, o julgamento do Tema 7 ("TAP Manutenção e Engenharia Brasil S.A. Ilegitimidade Passiva. Grupo Econômico. Responsabilidade Solidária. Empresa que não mais integra o grupo econômico"), devido à sua especificidade vinculada aos fatos de um caso concreto de alienação ativos para empresa ex-integrante de grupo econômico, aproxima-se bastante do procedimento-modelo alemão que possui origem no caso Telekom.
} 
tal como um produto do Banco Mundial. ${ }^{298}$ A segurança jurídica não é seletiva, mas para todos. Uma análise dos precedentes do TST revela entendimentos equilibrados e não indica somente decisões favoráveis ao empregador ou ao empregado.

A convicção de decisões reiteradas pode contribuir muito para a melhoria das condições sociais dos trabalhadores, bem como para fortalecimento da Justiça do Trabalho como instituição defensora dos direitos fundamentais daqueles que dependem de seu trabalho para sobreviver. A utilização do novo incidente, contudo, demanda cuidados, principalmente na seleção do recurso paradigma e utilização da técnica da distinção, sob pena de malferimento do acesso à justiça, tal como se procurou demonstrar o longo deste trabalho.

298 MAIOR, Jorge Luiz Souto. O conflito entre o novo CPC e o processo do trabalho. Disponível em: http://www.migalhas.com.br/arquivos/2015/7/art20150708-06.pdf. Acesso em: 31/01/17. 


\section{REFERÊNCIAS BIBLIOGRÁFICAS}

ALEMANHA. Capital Markets Model Case Act - KapMuG. Disponível em: http://www.gesetze-im-internet.de/englisch_kapmug/index.html/. Acesso em: 16/01/17.

ALMEIDA, Diogo Assumpção Rezende de. O case mangement inglês: um sistema maduro? Disponível em: http://www.epublicacoes.uerj.br/index.php/redp/article/view/21127/15217. Acesso em 30/07/16.

ANDREWS, Neil. O moderno processo civil: formas judiciais e alternativas de resolução

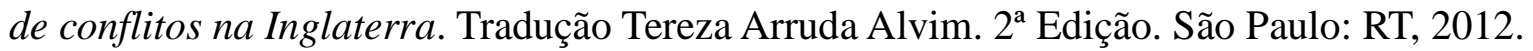

Multi-party proceedings in England: representative and group actions. Disponível em: http://scholarship.law.duke.edu/djcil/vol11/iss2/5. Acesso em 30/07/16.

ÁVILA, Humberto. Teoria dos princípios: da definição à aplicação dos princípios jurídicos. 17. ed., rev. e atual. São Paulo: Malheiros, 2016.

BARROSO, Luis Roberto. Neoconstitucionalismo e constitucionalização do Direito. $O$ triunfo tardio do Direito Constitucional no Brasil. Disponível em: http://jus.com.br/imprimir/7547/neoconstitucionalismo-e-constitucionalizacao-do-direito. Acesso em: 23/09/2015.

; MELLO, Patrícia Perrone Campos. Trabalhando com uma nova lógica: a ascensão dos precedentes no direito brasileiro. Disponível em: http://s.conjur.com.br/dl/artigo-trabalhando-logica-ascensao.pdf. Acesso em: 03/11/16.

BENEDUZI, Renato Resende. Introdução ao processo civil alemão. Salvador: JusPodivm, 2016.

BRASIL. Tribunal Superior do Trabalho (TST). Gabinete da Presidência (GP). Tabela dos recursos de revista repetitivos. Disponível em: http://www.tst.jus.br/presidencianurer/recursos-repetitivos. Acesso em: 16/01/17. 
BRASIL. Tribunal Superior do Trabalho (TST). Gabinete da Presidência (GP). Instrução normativa $\mathrm{n}^{\mathrm{o}}$ 37. Regulamenta os procedimentos em caso de Incidente de Uniformização de Jurisprudência (IUJ) no âmbito dos Tribunais Regionais do Trabalho, suscitado na forma do art. 896, $\S 4^{\circ}$, da Consolidação das Leis do Trabalho (CLT). Disponível em: http://www.tst.jus.br/web/guest/instrucoes-normativas. Acesso em: 25/01/17.

BRASIL. Tribunal Superior do Trabalho (TST). Gabinete da Presidência (GP). Instrução normativa n. ${ }^{\circ}$ 38. Regulamenta o procedimento do Incidente de Julgamento dos Recursos de Revista e de Embargos repetitivos à Subseção I Especializada em Dissídios Individuais (SBDI-1) do Tribunal Superior do Trabalho repetitivos. Disponível em: http://www.tst.jus.br/web/guest/instrucoes-normativas. Acesso em: 25/01/17.

BRASIL. Tribunal Superior do Trabalho (TST). Gabinete da Presidência (GP). Instrução normativa n. ${ }^{\circ}$ 39. Dispõe sobre as normas do Código de Processo Civil (CPC) de 2015 aplicáveis e inaplicáveis ao Processo do Trabalho, de forma não exaustiva. Disponível em: http://www.tst.jus.br/web/guest/instrucoes-normativas. Acesso em: 25/01/17.

BRASIL. Tribunal Superior do Trabalho (TST). Gabinete da Presidência (GP). Ato 491/SEGJUD.GP, de 23 de setembro de 2014. Fixa parâmetros procedimentais para dar efetividade à Lei n. 13015, de 21 de julho de 2014, que altera a Consolidação das Leis do Trabalho (CLT), aprovada pelo Decreto-Lei n. 5452, de $1^{\circ}$ de maio de 1943, para dispor sobre o processamento de recursos no âmbito da Justiça do Trabalho. Disponível em: http://www.tst.jus.br/web/guest/atos. Acesso em: 25/01/17.

BROCK, Ina; REKITT, Stefan. New reform of de capital markets model case act (the "KapMug”). Disponível em: http://www.lexology.com/library/detail.aspx?g=f82e443068d3-48ab-ba16-ff7084ff827f. Acesso em 27/08/16.

BUENO, Cassio Scarpinella. Amicus curiae no processo civil brasileiro: um terceiro enigmático. São Paulo: Saraiva, 2008.

. Manual de direito processual civil. $2^{\mathrm{a}}$ Edição. São Paulo: Saraiva,

2016.

BUSTAMANTE, Thomas da Rosa. Teoria do Precedente Judicial: a justificação e a aplicação de regras jurisprudenciais. São Paulo: Noesis, 2012. 
BUZAID, Alfredo. A crise do Supremo Tribunal federal. Estudos de direito. São Paulo, Saraiva, 1972.

CABRAL, Antonio do Passo. A escolha da causa-piloto nos incidentes de resolução de processos repetitivos. RT Revista de Processo: RePro, v. 39, n. 231, p. 201-223, maio 2014. Disponível em: https://www.academia.edu/10713934/A_escolha_da_causapiloto_nos_incidentes_de_resolu\%C3\%A7\%C3\%A3o_de_processos_repetitivos. Acesso em: 16/01/17.

A técnica do Julgamento-Alerta na Mudança de Jurisprudência Consolidada. Revista de Processo, ano. 38, n. 221, jul., 2013.

$O$ novo procedimento-modelo (Musterverfahren) alemão: uma alternativa as ações coletivas. Revista de Processo: RePro, v. 32, n. 147, p. 123-146, maio 2007.

CALICHMAN, Flávio. Enunciados de súmula do Tribunal Superior do Trabalho: considerações gerais, formação e aplicação. São Paulo: Faculdade de Direito - USP, 2002. Dissertação de mestrado.

CÂMARA, Alexandre Freitas. O novo processo civil brasileiro. $2^{\mathrm{a}}$ Edição. São Paulo: Atlas, 2016.

CAPONI, Remo. La decisione della causa nel mérito da parte della Corte di cassazione italiana e del Bundesgerichthof tedesco. Disponível em: academia.edu. Acesso em: 18/07/2016.

. Modelo europeu de tutela coletiva no processo civil: comparação entre

a experiência alemão e italiana. Revista de Processo: out/2011. v. 200. p. 235-269. Disponível

em:

http://www.revistadostribunais.com.br/maf/app/widgetshomepage/resultList/document?

$\&$ src $=$ rl\&srguid=i0ad82d9a0000015b155b2e86ccb6a080\&docguid=Icaa32520008711e196 $8 \mathrm{~d} 00008558 \mathrm{bdfc} \&$ hitguid=Icaa32520008711e1968d00008558bdfc \&spos=22\&epos $=22 \& \mathrm{t}$ $\mathrm{d}=4000 \&$ context $=75 \&$ crumb-action $=$ append $\&$ crumb-

label=Documento\&isDocFG=false\&isFromMultiSumm=true\&startChunk=1\&endChunk= 1. Acesso em: 27/03/17.

CAVALCANTI, Marcos. Incidente de resolução de demandas repetitivas e ações coletivas. Salvador: Juspodivm, 2015. 
CHIOVENDA, Giuseppe. Instituições de direito processual civil. Campinas: Bookseller, 2000, p. 8, Vol. II.

CNJ. Resolução n. ${ }^{o} 235$ do CNJ. Disponível em: http://www.cnj.jus.br/busca-atos-adm? documento=3155. Acesso em: 16/01/17.

COELHO, Luiz Fernando. Teoria Crítica do Direito. 3. ed. Belo Horizonte: DelRey, 2003.

CROSS, Rupert; HARRIS, J.W.. Precedent in English Law. $4^{\mathrm{a}}$ Edição. Oxford UK Print On. 1991.

CUNHA, Leonardo Carneiro da. Recursos Repetitivos. Disponível em: http://www.leonardocarneirodacunha.com.br/artigos/recursos-repetitivos/. Acesso em: 16/01/17.

DALAZEN, João Oreste. Apontamentos sobre a Lei 13.015/14 e impactos no sistema recursal trabalhista. Disponível em: http://juslaboris.tst.jus.br/handle/1939/85658. Acesso em: 14/11/16.

DIDIER Jr., Fredie, Cláusulas gerais processuais. Disponível em: <http://www.frediedidier.com.br/artigos /clausulas-gerais-processuais>. Acesso em 23/09/15.

BRAGA, Paula Sarno; OLIVEIRA, Rafael Alexandria de. Curso de direito processual civil. Vol. 2. 11 ${ }^{\text {a }}$ Edição. Salvador: JusPodivm, 2016.

; CUNHA, Leonardo Carneiro da. Curso de direito processual civil. Vol. 3. $13^{\text {a }}$ Edição. Salvador: JusPodivm, 2016.

DIDDIER JR., Fredie; MACÊDO, Lucas Buril de. Reforma no processo trabalhista brasileiro em direção aos precedentes obrigatórios: a lei $n .^{\circ}$ 13.014/15. Disponível em: http://aplicacao.tst.jus.br/dspace/handle/1939/79403. Acesso: em 10/03/2016.

DUXBURY, Neil. The nature and authority of precedent. Estados Unidos: Cambrigde, 2008. 
FENOLL, Jordi Nieva. La enunciación de los motivos de casación em las leyes procesales. In Jurisdicción y processo. Madrid: Marcial Pons, 2009, pp. 447-477.

FERRAZ Jr., Tércio Sampaio. Introdução ao Estudo do Direito. Técnica, decisão, dominação. $7^{\text {a }}$ ed. São Paulo: Atlas, 2013.

GARCIA, Gustavo Filipe Barbosa. Lei 13.015/14 e inovações no processo do trabalho. Disponível em: http://www.migalhas.com.br/dePeso/16,MI204724,51045Lei+1301514+e+inovacoes+no+processo+do+trabalho. Acesso em 10/03/2016.

GIDI, Antonio. A class action como instrumento de tutela coletiva dos direitos: as ações coletivas em uma perspectiva comparada. São Paulo: Editora Revista dos Tribunais, 2007.

GOODHART'S, Arthur L.. Determining the ratio decidend of a case. The Yale Law Journal Company, Inc. Disponível em: www.umiacs.umd.edu/ horty/courses/.../goodhart1930-ratio.pdf . Acesso em: 26/01/17.

GRAU, Eros Roberto. $O$ direito posto e o direito pressuposto. $9^{\mathrm{a}}$ ed. São Paulo: Malheiros, 2014.

INGLATERRA. Civil procedure rules (CPRs). Disponível em: https://www.justice.gov.uk/courts/procedure-rules/civil/rules/part19\#19.1. Acesso em 06/08/2016.

LEAL, Victor Nunes. Passado e futuro da 'Súmula do STF'. Disponível em http://bibliotecadigital.fgv.br/ojs/index.php/rda/article/view/43387. Acesso em 09/01/16.

LEONEL, Ricardo de Barros. Reclamação constitucional. São Paulo, RT, 2011.

LIMA, Firmino Alves. A lei $n .^{\circ} 13.015 / 2014$ como introdutora dos julgamentos de recursos repetitivos e da teoria dos precedentes no processo trabalhista. Rev. TST, Brasília, vol. 80, no 4, out/dez 2014.

LUCON, Paulo Henrique dos Santos. Devido processo legal substancial. In: DIDIER Jr. Fredie (Org.). Leituras complementares de processo civil. 6. ed. Salvador: JusPodivm, 2008 .

Evolução da reclamação constitucional e seu emprego para assegurar a autoridade dos precedentes. In: Processo civil: homenagem a José Ingácio Botelho de Mesquita. TUTTI, José Rogério Cruz e. (coord. et al). São Paulo: Quartirer Latin, 2013. 
MALLET, Estêvão. A jurisprudência sempre deve ser aplicada retroativamente? Disponível em: https://www.trt9.jus.br/internet_base/arquivo_download.do? evento=Baixar\&idArquivoAnexadoPlc=1511042. Acesso em: 08/01/17.

Considerações sobre a homogeneidade como pressuposto para a tutela coletiva de direitos individuais. Revista Faculdade Direito Universidade São Paulo, v. 105, p. 111-142, jan./dez.2010.

. Notas sobre o sistema recursal do projeto de Código de Processo Civil e o processo do trabalho. Revista do Tribunal Superior do Trabalho, v. 78, p. 53-69, 2012.

. Reflexões sobre a Lei $n$. 13.015/2014. Revista do Tribunal Superior do Trabalho, v. 80, p. 74-111, 2014.

MARINONI, Luiz Guilherme. Aproximação crítica entre as jurisdições de civil law e de common law e a necessidade de respeito aos precedentes no Brasil. Capítulo XXVI. DIDIER JR. Fredie (coord.). Teoria do Processo - Panorama Doutrinário Mundial Vol. 2. Salvador: Ed. JusPodivm, p. 533-588.

Curso de processo civil: teoria geral do processo, V. 1. $3^{\text {a }}$ ed. São Paulo: Revista dos Tribunais, 2008.

O STJ enquanto corte de precedentes. $3^{\mathrm{a}}$ ed. São Paulo: Revista dos Tribunais, 2014.

Precedentes obrigatórios. $4^{\text {a }}$ Edição. São Paulo: Revista dos Tribunais,

2016.

; ARENHART, Sérgio Cruz; MITIDIERO, Daniel. Novo Código de Processo Civil Comentado. $2^{\text {a }}$ Edição. São Paulo: Revista dos Tribunais, 2016.

MARRAFON, Marco Aurélio. Para compreender (e superar) os pilares do positivismo jurídico (parte 2). Disponível em: <http://www.conjur.com.br/2015-mai-25/constituicaopoder-preciso-compreender-superar-positivismo-juridico-parte>. Acesso em: 25/05/2015. 
MARTINS, José Renato Silva. Dogma da neutralidade judicial. Rio de Janeiro: Lumen Juris, prefácio, XII e XIII.

MEDINA, José Miguel Garcia. Novo Código de Processo Civil Comentado. $3^{\text {a }}$ Edição. São Paulo: Revista dos Tribunais, 2015.

MELLO, Patrícia Perrone Campos. Precedentes e vinculação. Instrumentos do stare decisis e prática constitucional brasileira. Disponível em: http://bibliotecadigital.fgv.br/ojs/index.php/rda/article/view/43370/44673. Acesso em 10/03/16.

MELlO, Raimundo Simão de Melo. Ação Civil Pública na Justiça do Trabalho. 2a. ed. São Paulo: LTR, 2004.

MESQUITA, José Ignácio Botelho de. A súmula da jurisprudência dominante no Supremo Tribunal Federal, in Teses, Estudos e Pareceres de Processo Civil, vol. 2, São Paulo: RT, 2005, pp. 216 e ss.

Da uniformização da jurisprudência - uma contribuição para seu estudo, in Teses, Estudos e Pareceres de Processo Civil, vol. 2, São Paulo: RT, 2005, pp. 227 e ss.

jan./2006, p. 250-257.

Processo civil e processo incivil. Revista de Processo, vol. 131,

MITIDIERO, Daniel. Cortes Superiores e Cortes Supremas. São Paulo: Revista dos Tribunais, 2013.

- Fundamentação e precedente: dois discursos a partir da decisão judicial. Revista de Processo: RePro, v. 37, n. 206, p. 61-78, abr. 2012.

NERY JR., Nelson; ANDRADE NERY, Rosa Maria de. Comentários ao Código de Processo Civil. São Paulo: RT, 2015.

NERY JR. Nery; ABBOUD, Georges. Stare Decisis x Direito Jurisprudencial. in DIDIER JR., Fredie et alli (coords.), Novas Tendências do Processo Civil. Salvador: JusPodivm, 2013, p. 483/512. 
NEVES, Antônio Castanheira. Questão de facto - Questão de direito. Coimbra: Almedina, 1967.

NOGUEIRA, Gustavo Santana, Precedentes vinculantes no direito comparado $e$ brasileiro. $2^{\text {a }}$ Edição. Salvador: JusPodivm, 2015.

NUNES, Aluisio Gonçalves de Castro Mendes. O incidente de resolução de demandas repetitivas no novo Código de Processo Civil. Disponível em: https://www.academia.edu/15300046/O_incidente_de_resolu \% $3 \%$ A7\%C3\%A3o_de_demandas_repetitivas_do_novo_C \%C3\%B3digo_de_Processo_Civil; Acesso em 29/07/16.

NUNES, Dierle. Alguns requisitos democráticos da aplicação dos precedentes e Novo $C P C$. Disponível em: <http://emporiododireito.com.br/alguns-requisitos-democraticosdaplicacao-dos-precedentes-e-novo-cpc/>. Acesso em: 25/09/15.

; HORTA, André Frederico. Aplicação de Precedentes e Distinguishing

no CPC/2015. Uma breve introdução. Disponível em:

https://www.academia.edu/12353024/APLICA

\%C3\%87\%C3\%830_DE_PRECEDENTES_E_DISTINGUISHING_NO_CPC_2015.

Acesso em 22/06/16.

; Rafaela Lacerda; Newton Rodrigues Miranda. O uso do precedente judicial na prática judiciária brasileira: uma perspectiva crítica. Rev. Fac. Direito UFMG, Belo Horizonte, n. 62, pp. 179 - 208, jan./jun. 2013.

; Rafael Dilly Patrus. Uma breve notícia sobre o procedimento modelo alemão e sobre as tendências brasileiras de padronização decisória: um contributo para o estudo do incidente de resolução de demandas repetitivas brasileiro, in DIDIER JR., Fredie et alli (coords.), Novas Tendências do Processo Civil. Salvador: JusPodivm, 2013, p. $469 / 482$.

NUNES, Dierle; BAHIA, Alexandre. Processo, jurisdição e processualismo constitucional democrático na América Latina: alguns apontamentos. Disponível em: www.pos.direito.ufmg.br/rbepdocs/101061096.pdf . Acesso em 21/07/16.

NOGUEIRA, Gustavo Santana, Precedentes vinculantes no direito comparado $e$ brasileiro. $2^{\text {a }}$ Edição. Salvador: JusPodivm, 2015. 
PORTUGAL. Tribunal Constitucional. Acórdão $n^{o}$ 810/93. Disponível em: http://www.tribunalconstitucional.pt/tc/acordaos/19930810.html. Acesso em: 08/01/17.

REIS JÚNIOR, Ari Timóteo. Hermenêutica e aplicação do Direito. Breves apontamentos sobre a interpretação jurídica no paradigma contemporâneo. Disponível em: <http://jus.com.br/artigos/18553/hermeneutica-e-aplicacao-do-direito>, acesso em: 29/09/15.

RENE, David. Os grandes sistemas do direito contemporâneo. Tradução Hermínio

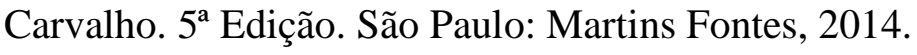

RODRIGUES, Roberto de Aragão Ribeiro Rodrigues. As ações-teste na Alemanha, Inglaterra e legislação brasileira projetada. Disponível em www.agu.gov.br/page/download/index/id/9923690. Acesso em 27/08/16.

ROSSONI, Igor bimkowski. O "Incidente de Resolução de Demandas Repetitivas" e a Introdução do Group Litigation no Direito Brasileiro: Avanço ou Retrocesso? Disponível em: $\quad$ http://www.tex.pro.br/home/artigos/44-artigos-dez-2010/4740-o-incidente-deresolucao-de-demandas-repetitivas-e-a-introducao-do-group-litigation-no-direitobrasileiro-avanco-ou-retrocesso. Acesso em 30/07/16.

SARLET, Ingo Wolfgang; MARINONI, Luiz Guilherme; MITIDERO, Daniel. Curso de direito constitucional. São Paulo: Editora Revista dos Tribunais, 2012.

SARMENTO, Daniel. A dimensão objetiva dos direitos fundamentais: fragmentos de uma teoria. In: Jurisdição Constitucional e Direitos Fundamentais. coord José Adécio Leite Sampaio. Belo Horizonte: Del Rey, 2003.

A Ponderação de Interesses na Constituição. Rio de Janeiro: Lumen Juris, 3' ed., 2003.

SCOFIELD, Robert G. Goodhart's Concession: Defending Ratio Decidendi From Logical Positivism and Legal Realism in the First Half of the Twentieth Century. The King's College Law Journal. Disponível em: <http://www.legalargument.net/assets/kclj_162_Scofield_ 311to328.pdf.> Acesso em: 23/06/16. 
SICA, Heitor Mendonça. Brevíssimas reflexões sobre a evolução do tratamento da litigiosidade repetitiva no ordenamento brasileiro, do CPC/1973 ao CPC/2015. Revista de Processo, vol. 257/2016, p. 269 - 281, Jul / 2016.

SOUTO MAIOR, Jorge Luiz. A quem interessa essa "reforma” trabalhista. Disponível em: http://www.jorgesoutomaior.com/blog/a-quem-interessa-essa-reforma-trabalhista. Acesso em: 17/11/17.

O conflito entre o novo CPC e o processo do trabalho. Disponível em: http://www.migalhas.com.br/arquivos/2015/7/art20150708-06.pdf. Acesso em: $31 / 01 / 17$

STRECK, Lenio; ABBOUD, Georges. O NCPC e os precedentes - afinal do que estamos falando?, in DIDIER JR., Fredie et alli (coords.), Precedentes - Coleção Grandes Temas do Novo CPC, vol. 3, p. 175/182.

O que é isto - o sistema (sic) de precedentes no CPC? Disponível em: http://www.conjur.com.br/2016-ago-18/senso-incomum-isto-sistema-sicprecedentes-cpc. Acesso em: 16/11/16.

STÜRNER, Rolf. Sobre as reformas recentes no direito alemão e alguns pontos em comum com o projeto para um novo Código de Processo Civil. Revista de Processo: março/2011. Ano 36. v. $193 . \quad$ Disponível em: http://www.revistadostribunais.com.br/maf/app/resultList/document?

$\&$ src $=$ rl\&srguid=i0ad82d9a0000015b155271f0c27634b8\&docguid=Ic6730720659311e0b d4c0000855dd350\&hitguid=Ic6730720659311e0bd4c0000855dd350\&spos=1\&epos=1\&td $=1952 \&$ context $=34 \&$ crumb-action $=$ append \&crumb-

label=Documento\&isDocFG=true \&isFromMultiSumm=true \&startChunk=1\&endChunk=1 . Acesso em: 27/03/17.

TARUFFO, Michele. Dimensiones del precedente judicial. In Páginas sobre justicia civil. Madrid: Marcial Pons, 2009, pp. 541-554.

Funzione e problemi attuali della Corte di cassazione. In Il vértice ambíguo - Saggi sulla Cassazione Civile. Bologna: Il Mulino, 1991.

Le funzioni delle Corti Supreme tra uniformità e giustizia, in DIDIER JR., Fredie et alli (coords.), Precedentes. Salvador: JusPodivm, 2015, p. 251/262. 
Observações sobre os modelos processuais de civil law e de common law. Revista de Processo: RePro, São Paulo, n. 110, v. 28, abr/jun 2003, p. 141-158.

Precedente e jurisprudência. Trad. Chiara de Teffé. Civilistica.com. Rio de Janeiro, a. 3, n. 2, jul.-dez./2014. Disponível em: <http://civilistica.com/precedenteejurisprudencia/>. Acesso em: 23/06/16.

. Some Remarks on Group Litigation in Comparative Perspective. InDuke Journal of Comparative \& International Law. n. 11. 2001. Disponível em http://scholarship.law.duke.edu/djcil/vol11/iss2/12. Acesso em: 2703/17.

TEMER, Sofia. Incidente de resolução de demandas repetitivas. $2^{\mathrm{a}}$ Ed. Salvador: JusPodivm, 2017.

THEODORO JR., Humberto; NUNES, Dierle; BAHIA, Alexandre Melo Franco; PEDRON, Flávio Quinaud. Novo CPC - Fundamentos e Sistematização. $3^{\mathrm{a}}$ Ed. Rio de Janeiro/RJ: Forense, 2016.

TUCCI, José Rogério Cruz e. $O$ regime do precedente judicial no novo $C P C$, in DIDIER JR., Fredie et alli (coords.), Precedentes - Coleção Grandes Temas do Novo CPC, vol. 3, p. $445 / 457$.

Direito processual civil europeu contemporâneo. São Paulo: LEX, 2010.

WAMBIER, Teresa Arruda Alvim (coord.). Direito jurisprudencial. São Paulo: Revista dos Tribunais, 2012.

Estabilidade e adaptabilidade como objetivos do direito: civil law e common law. Revista de Processo, vol. 172, p. 121, Jun/2009. DTR\2009\337. Disponível em:

http://www.egov.ufsc.br/portal/sites/default/files/estabilidade_e_adaptabilidade_como_obje tivos_do_direito_civil.pdf. Acesso em: 23/06/16.

Distinção entre questão de fato e questão de direito para fins de cabimento de recurso especial. Revista de Processo, vol. 92. 
; DANTAS, Bruno. Recurso especial, recurso extraordinário e a nova função dos tribunais superiores no direito brasileiro. $3^{\mathrm{a}}$ edição, revista, atualizada e ampliada. São Paulo: Revista dos Tribunais, 2016.

WOLKMER, Antônio Carlos. Introdução ao pensamento jurídico crítico. 9. ed. São Paulo: Saraiva, 2015.

WOOLF, Harry [Lord]. Access Justice: final report. Disponível em: http://webarchive.nationalarchives.gov.uk/

+/http://www.dca.gov.uk/civil/final/contents.htm. Acesso em 27/08/16.

ZANETI JR., Hermes. Cortes Supremas e interpretação do direito. In O Papel da jurisprudência no STJ (coord. Isabel Gallotti, e outros). São Paulo: RT, 2014

. O valor vinculante dos precedentes: teria dos precedentes normativos formalmente vinculantes. $2^{\text {a }}$ Edição. Salvador: JusPodivm, 2015.

Thiago Henrique Ament 